\title{
A Critical Review on Artificial Intelligence Models in Hydrological Forecasting How Reliable are Artificial Intelligence Models
}

\author{
Dibie Chidubem Damian \\ Department of Civil Engineering Science \\ University of Johannesburg \\ South Africa
}

\begin{abstract}
There has been a variety of techniques employed in the forecasting hydrological events. These techniques have shown efficacies in some circumstances and also shown poor performance in some events as the case may be. Analysis of hydrological events like sediment transport, river discharge, water quality; require in depth of knowledge of complex variables associated with the catchment that inter-relate so as to have a better clarity of the event in order to carry out a better simulation and subsequently forecasting. However, the description of these hydrological processes has been hampered by lack of access to data over a variety of parameters for a long period and the issues of missing data as well. These have brought about the undermining of numerical models and therefore made the introduction of Artificial intelligence (AI) models expedient and inevitable. AI models have become a viable option in describing hydrological processes and this article reviewed thirty journals over a span of eleven years where some AI models ( Artificial Neural Networks (ANNs), Fuzzy Logic (FL) and Adaptive Neuro-Fuzzy Inference System (ANFIS) ) have been used in predicting hydrological events such as: Streamflow, Rainfall-Runoff, Groundwater Modelling, Water Quality Modelling and Sediment Load Prediction. The results of performance of the AI models in comparison with other conventional models in those reviewed articles showed AI models performed better than numerical models and thus, elucidating their reliability in describing hydrological events
\end{abstract}

Keywords: Artificial Neural Networks (ANNs), Fuzzy Logic (FL), Adaptive Neuro-fuzzy Inference System (ANFIS)

\section{INTRODUCTION}

Hydrology is the scientific approach in the study of water as well as its properties, distribution, the earth surface effects, soil and the atmosphere (McCuen, 2016). A plethora of hydrological activities are quite nebulous whereby these activities are greatly affected by a variety of interconnected variables (Daliakopoulos, et al 2005). Researchers in Hydrology have had to deal with problems associated with various hydrological features like transportation of sediments and contamination, flood, rainfall runoff (ASCE, 2000). The physical models also known as numerical models have been the conventional approach to address most of hydrological problems in the previous decades (Javadi and Al-Najjar, 2007). These models need a sizable amount of data about the various parameters which describe the complex features of the hydrological activity and these large data of these parameters also require high degree of accuracy for these physical models to function with appreciable efficacy. Unfortunately, there is a snag in getting access to these data as limitations of financial implications, time, availability of data which poses a real threat to the application of physical models which ultimately causes deficiency in proper water management planning and decisions (Krishna et al. 2008; Coppola et. al 2005).

Hence, these constraints have subsequently made the development of Artificial Intelligence (AI) a much-needed approach. Artificial Intelligence can be defined according to Džeroski et al (1997) as "study of ways in which computers can perform tasks that demand intelligent behaviour" in the areas of learning, forecasting, problem solving. Various techniques can be classified under this innovative approach such as Artificial Neural Network $(A N N)$, Fuzzy Logic (FL) and Adaptive Neuro-fuzzy Inference System (ANFIS). AI approaches have been known to be highly effective in addressing problems whose rules are difficult to describe as typified in hydrological activities (Chen et al, 2008). Hence, AI has become more resourceful and preferred to the conventional physical modelling methods in hydrology. (Chen et al, 2008; Basheer and Hajmeer, 2000). However, if the AI models are to ultimately replace physical models in describing hydrological activities, the right dimension to look at is "How reliable are these Artificial Intelligence models" Their reliability will consequently pave the way for AI models to replacing the conventional models already in use.

Previous reviews have been done on models describing hydrological activities such as Alagha et al. (2012) that did a review on Artificial Intelligence in Hydrological processes, only two techniques were reviewed which are ANN and Support Vector Machine (SVM) and their level of performance was not clearly stated for each hydrological process illustrated. More so, Gupta et al. (2015) did a critical review on hydrologic models which concentrated on physical based models with little information on the hydrological processes where they were employed and no information on their performance output in forecasting. Kingston et al. (2008) also did review of AI techniques and their Application in Hydrology but no hydrologic process using AI techniques was described thus their performance could not have been mentioned. 
The main aim or focus of this review is to elucidate on the application of three AI techniques which are Artificial Neural Network (ANN), Fuzzy Logic (FL) and Adaptive Neuro-Fuzzy Inference System (ANFIS) and their prediction usage in various hydrological processes.

\section{A. Artificial Neural Network (ANN)}

\section{- Overview}

The Neural network tend to a certain extent adopt the human approach of thinking for a plethora of purposes which may be natural or anthropogenic. ANNs are models that adopt the biological network of how neurons are connected and transmit data in the human brain in its operation. They are statistical tools that do not rely on assumptions and very resourceful in various tasks such as forecasting, optimization, clustering, etc. (Besaw and Rizzo, 2007; Jain et al 1996). In the field of research, ANNs are currently being utilized for the purpose of attaining solutions to sizable problems like pattern recognition, optimization and prediction (Jain et al., 1996) The basic layout of ANN architecture comprises three layers which are the input layer, the output layer and the hidden layer which may be one or more. Each layer consists of elements which are interconnected to one another; these elements are called nodes or neurons. A neuron is an element that executes lots of processes such as taking in some input data, assigning weights to those data, summing up the products of the weight with its respective input data, attaching a bias to it. The subsequent result is then modified by a function known as the activation function. The end result of these processes is known as the output. Individual neurons in each layer are connected in such a way that there is link between neurons in a layer and the neurons in the subsequent layer with determined weights that show their level of interrelationship and not linked to neurons in the same layer as it (Yesilnacar et al. 2008).

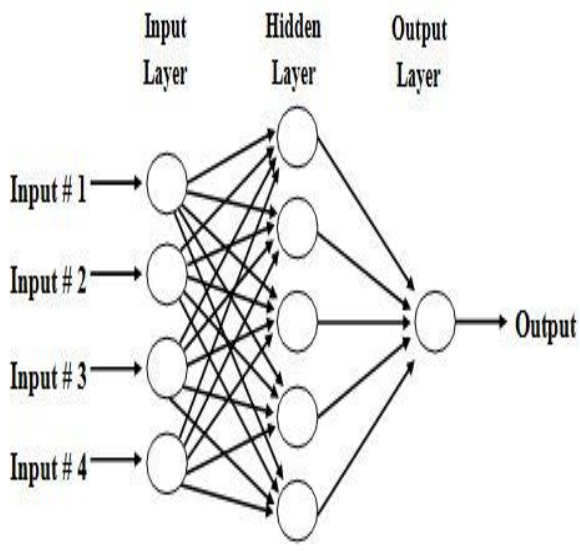

1: ANNs typical structure

(Chen et al, 2008)

Figure

The architecture of the network is the pivotal point that determines the type of ANN to be used and how the components of the ANN are configured. (Palani, et al. 2008; Starrett, et al. 1998). Since the architecture of the network is responsible for pattern of connection, amount of weights to be assigned, how information is transmitted through the network; the choice of architectural network has a great impact on the efficacy of the ANN, thus it is seen as the principal aspect while developing the ANN model. More so, it is the most tedious aspect to be done while developing the ANN model (Chen and Chang, 2009; Singh and Datta, 2007)

\section{- $\quad$ The Learning/Training process of ANN}

The training process is carried out by the model through the comparing the results from the model and the actual known data; this process in iterative and concurrently modifying as well until the results attain a rate of error which is very minute. ANN based on their characteristics give more reliable results than the linear models (Priddy and Keller, 2005).

For ANNs to be able to outline the nebulous relationships between input data and the expected output data, it must undergo a training process which laborious to estimate through other techniques (Lin and Chen, 2006). Physical models carry out their operations through a specified set of rules, whereas ANNs undergo a learning process by detecting patterns which illustrates the relationship or pattern between the input variables and the subsequent output variables to solve the problem from the stated examples (Jain et al 1996). Subsequently, a peculiar relationship that is mathematical and specific to the problem is modelled by the ANN (Starrett, et al. 1998).

The termination of the training phase is done when one of the stated criteria is attained (Maier and Dandy, 2001). These criteria are:

i. When a specific number learning cycle is given to the network

ii. When the error in training has been optimised to a permissible minute value

iii. When it is impossible to get a better result than the predictions already made by the model

Furthermore, the training of any $\mathrm{NN}$ is the process where the magnitude of weights of each node are ascertained reliably. This is done by modifying the weights with feasible values and then subsequently plotting the error in space as shown below:

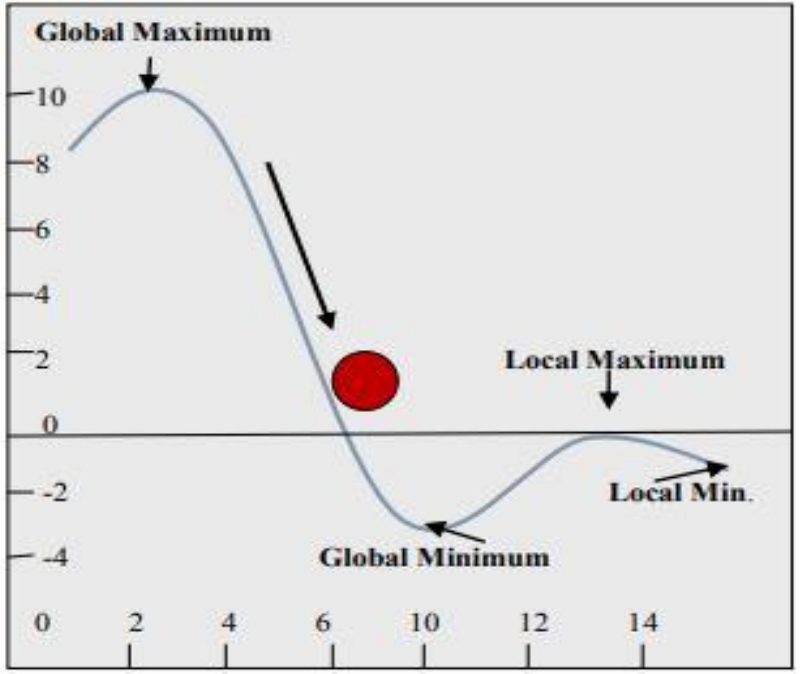

Figure 2: A schematic representation of an error surface (Sibanda and Pretorius, 2012) 
In the course of developing the ANN model, the data set of the input parameter(s) is divided and classified into three subsets which are the "training subset, test subset and the validation subset" The training subset is applicable while in the learning or training phase for the purpose of adjusting or modifying the weights that link neurons in a layer to neurons in the different layers of the network (El Tabach, et al. 2007). More so, the test subset is applicable also in the training phase but in a different context in order to examine the response of the untrained data in the test subset. The response gotten during the testing might bring about modification of the network architecture. The final subset which is the validation subset is used which is also distinct from the other two subsets is adopted after the choice of an appropriate network layout has been adopted in order to ascertain its efficacy and accuracy before utmost application (Basheer and Hajmeer, 2000).

\section{B. FUZZY LOGIC (FL)}

\section{- Overview}

Fuzzy actually means vague or not clear enough. Looking at a preceding logic which is Boolean logic that utilises two values only which may be true or false. In some other cases 0 or 1 and in other aspects it takes low or high. Fuzzy logic seeks to further extend the concept to a more detailed description which is all inclusive such as extent of true or false; adopting values ranging from 0 to 1 ; as well as how low or high such as very low, medium, very high as the case may be. Fuzzy logic is a continuation and upgrade of Boolean logic (Makkar, 2018).

Fuzzy logic (FL) has to do with fuzzy sets theory whereby it describes objects classes with no specific boundaries and of which membership of an object in a fuzzy set is a matter of degree. Generally, FL is a suitable way of mapping input space to output space. FL is a non-probabilistic method that describes nebulous or fuzzy parameters. For instance, when there is communication between people, the accuracy of describing features of an object is mostly never attained. Instead nebulous terms like "low", "high", "medium", "cold", "warm", "hot" are used. These nebulous terms however do not have any boundaries but are comprehended with respecting to the person's reasoning and experience to the extent to which the conditions are described by the terms (Michalewicz and Fogel, 2013). Fuzzy Logic (FL) operates similarly to humans based on indefinite instead of precise description through the use of fuzzy set theory and this is utilised to what extent an object is able to satify a nebulous description through a mathematical framework (Russell and Norvig, 2003). In this mathematical framework, membership function $m_{i}(x)$ is utilised for the purpose of description of the degree of membership of an object $x$ to a set $i$. In a scenario where the boundaries of the set is defined and sharp as seen in classical theory then $x$ would be a member of the set $I\left(m_{i}(x)=1\right)$ or $x$ would not be a member of the set $\left(m_{i}(x)=0\right)$. On the contrary, fuzzy set theory would make the function $m_{i}(x)$ take up a variety of values between 0 and 1 in order to state the extent of truth embedded in a statement that $x$ is a member of $i$.

\section{$\bullet$}

\section{FUZZY RULE-BASED INFERENCE}

"The Fuzzy rule-based inference" (FRB) makes it possible for models to reason when situations are partially true. This is done via the utilization of fuzzy rules which takes the form of conditional statements and converts inputs to outputs. For instance, a fuzzy rule describing the relationship of rainfall intensity and rainfall duration to the volume of runoff is given by:

$\begin{array}{cccc}\text { IF } & \text { rainfall intensity } & \text { is } & \text { High } \\ \text { AND } & \text { rainfall duration } & \text { is } & \text { Long } \\ \text { THEN } & \text { runoff } & \text { is } & \text { High }\end{array}$

In this case "rainfall intensity", "duration of rainfall" and "runoff volume" are all captured in the fuzzy sets. The FRB inference procedures are stated in the four main steps below:

Step 1. Fuzzification: in this stage, crisp values are used as the input variables and converted into the appropriate fuzzy sets with respect to their degree of membership. For instance is rainfall intensity is defined the sets "low", "medium" and "high" and duration of rainfall is defined by the sets "short", "medium" and "long" for all given crisp values of rainfall intensity $I_{i}$ and rainfall duration $D_{i}$. The first thing to do is to determine or ascertain the degree of membership of these crisp values to their respective fuzzy sets, as shown in figure 2 below.

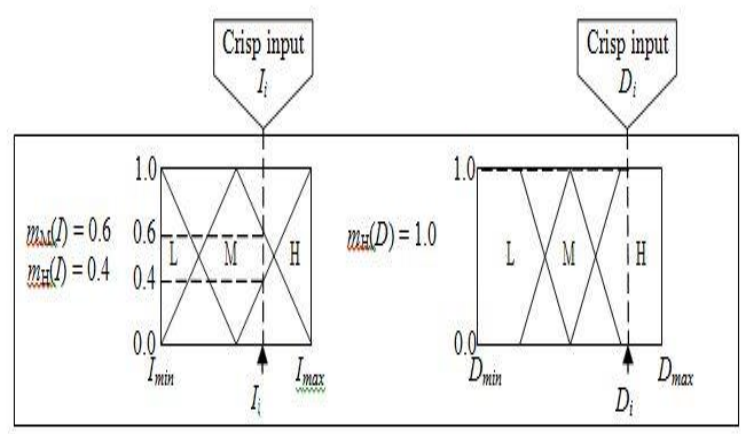

Figure 3: Fuzzyfication (Negnevitsky, 2005).

Step 2. Rule Evaluation: In this phase, the inputs that have been fuzzified are then infused into the rule antecedents for instance IF "rainfall intensity is Low, IF "rainfall duration" is Short; for the estimation of degree of truth THEN "run off volume" is Low. More so, in the case whereby the antecedents are multiple for a given set of rules, it has to be resolved into a single number with the aid of the fuzzy operators AND or OR. These fuzzy operators operate quite similar to those in use in classical sets and can be expressed as the degree or extent to which an object $x$ in both sets which is $\mathrm{A} \cap \mathrm{B}$ or the extent to which $x$ is in either set which is expressed by $\mathrm{A} \cup \mathrm{B}$. The min-max functions that was suggested is given by: 


$$
\begin{aligned}
& m_{A \cap B}(x)=\min \left[m_{A}(x), m_{B}(x)\right] \\
& m_{A \cup B}(x)=\max \left[m_{A}(x), m_{B}(x)\right]
\end{aligned}
$$

Equation 1 describes the AND operator while Equation 2 describes the OR operator (Kingston et al., 2008). As shown in a previous work done, it was however suggested that the performance difference of fuzzy systems depending on the operator in use is negligible (Bardossy and Duckstein, 1995). There is another fuzzy operator being used is known as the NOT or the complement which describes the degree or extent to which an object $x$ is not a member or does not belong to $\mathrm{A}$ (which is $\mathrm{A}^{\mathrm{c}}$ )

$$
m_{A^{c}}(x)=1-m_{A}(x)
$$

The process of the evaluation phase is shown the figure 4 below:

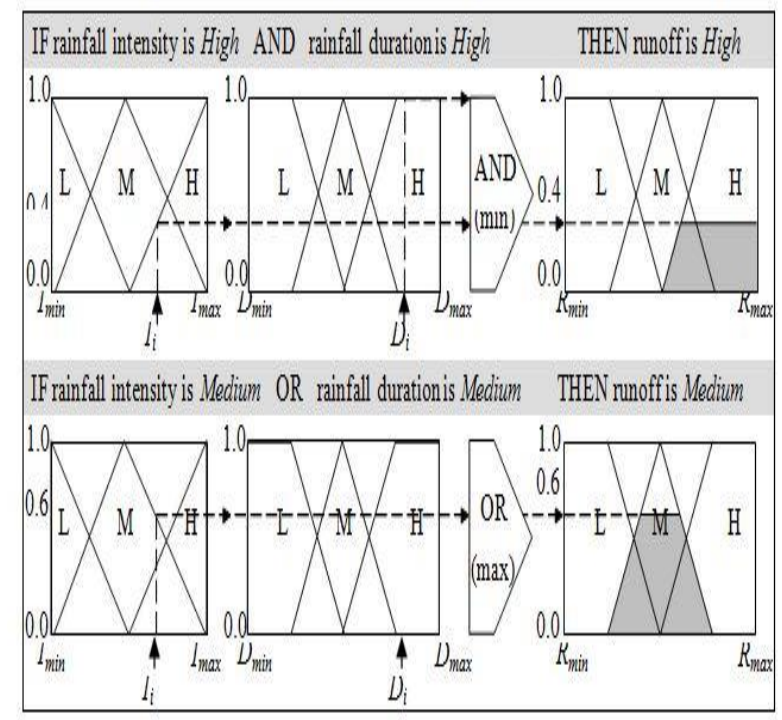

Figure 4: Rule Evaluation

(Negnevitsky, 2005).

Step 3. Aggregate of rule outputs: This phase comprises a set of rules that interpret the way the functions respond to different conditions and this is known as rule base. Fuzzy inference enables for several fuzzy rules in the rule base whether partial or simultaneous (Bardossy and Duckstein, 1995). So the responses from the different rules fired needs to be infused or aggregated into a single fuzzy set as shown in the figure 5 below:

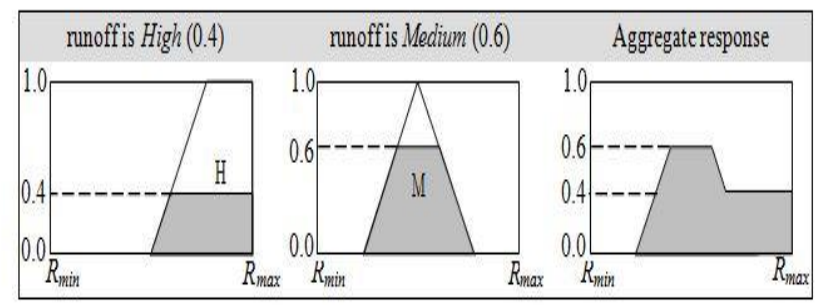

Figure 5: Aggregate of rule output (Negnevitsky, 2005)
Step 4. Defuzzification: After the responses of the set of rules have been infused, the resultant fuzzy set will consequently be defuzzified or converted into a single crisp output. This is popularly done by computing the mean or centroid of the fuzzy set negligible (Bardossy and Duckstein, 1995) which is shown in figure 6 below:

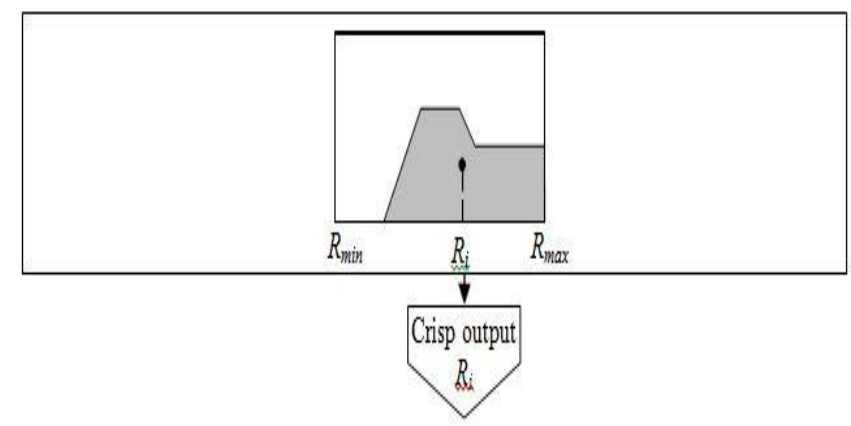

Figure 6: Defuzzification (Negnevitsky, 2005)

The fuzzy mean is then computed by as illustrated

$$
\text { Fuzzy Mean } R_{i}=\frac{\sum_{R=a}^{b} m_{A}(R) R}{\sum_{R=a}^{b} m_{A}(R)}
$$

This implies the point at which the vertical line divides the set into equal masses

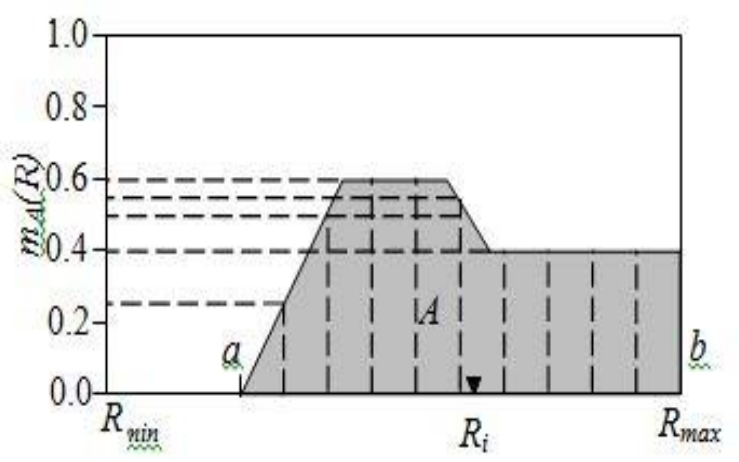

Figure 7: Estimating the mean of the aggregate fuzzy set for defuzzification (Kingston, et al. 2008)

\section{ADAPTIVE NEURO-FUZZY INFERENCE SYSTEM (ANFIS) \\ - Overview}

ANFIS is a hybrid form of ANN and FL for the purpose of improved simulation and better forecasting especially in the field of hydrology (Galavi and Shui, 2012). ANFIS technique has benefited immensely from the advantages of ANN and FL. ANFIS approach is derived from the characteristic features of ANN such as the leaning abilities, optimization and the structure of connection; also infused with the FL unique abilities to emulate human way of thinking and the usage of knowledge from experts.

ANFIS was initially developed by Jang (1993); this approach neutralizes the main limitation of FL modelling with respect to no systematic layout in the design of fuzzy controller through the learning abilities of ANN, it also does its structure organisation by itself and adaptation embedded in an interactive procedure (Chang and Chang, 2006). Knowledge of the system is utilised through the 
fuzzy if-then rules and its applicable parameters such as the membership functions are fine tuned throught the data processing of ANN.

In the ANFIS model variables relate with one another with the aid of the if-then rules for instance if discharge is high today; then it very much likely that discharge will be high tomorrow. The rule is a qualitative way of describing the relationship between discharge today and discharge tomorrow. To develop a model that is operational, the term "high" has to be precisely defined. Any data that is considered as being "high" is classified in a fuzzy set. The usage of membership functions (MF) is applicable to describe a range of values $[0,1]$ with respect to the crisp data that relates to the fuzzy set in question (Jang et al., 1997). It implies that value of membership 0 means nonmembership while the value of 1 implies full membership of the object in the fuzzy set. Any value between ( 0 to 1 ) denotes partial membership. There are two techniques which are mostly used to describe parameters of MF which are back hybrid learning algorithm and back propagation algorithm (Firat and Güngör, 2007).

There are determinant or pivotal factors that greatly determine the architecture of ANFIS and its model compatibility which are the number of rules, the number and also choice of MFs. However, there are no procedures in the choice of MFs and its number which a network needs to bring output error to a minimum or to take performance index to a maximum (Babuška and Verbruggen, 2003). There have been different ideologies on the which MF is most suitable at the fuzzification phase during model development. One ideology implies that triangular MF is most suitable to practical applications (Kisi, 2006); however, another ideology implies that Gaussian MF has shown better performance in comparison with triangular MF as indicated by the following (Zounemat-Kermani and Teshnehlab, 2008). Furthermore, MF can adopt any form and whichever produces a minimum MSE "(Mean Square Error)" will be the most suitable choice (Galavi and Shui, 2012).

\section{- $\quad$ ANFIS architecture and algorithm}

The ANFIS architecture is such that it is a hybrid network which examines the most suitable fuzzy rules so as to function appropriately on the task to be executed. The methodology of ANFIS is designed to develop a FIS, utilising the data set of imput-output and modify the parameters of the MF by either the use of hybrid algorithm of least squares estimator and back propagation or back propagation algorithm (Swain and Umamahesh, 2003). For the purpose of demonstrating ANFIS architecture, which is illustrated via the mapping of FIS to ANN, a "Takagi Sugeno (TS) fuzzy model" is examined in figure 8a. This results to the emergence of some parameters in the subsequent part of which a mathematical expression which represents the contribution of individual entry in the output. For instance, input variables $x_{1}$ denotes the initial lag of the water level while $x_{2}$ denotes the latter; the output variable (f) denotes the current water level are shown in the explanation of the model architecture. In a case where each of the input variables has two MFs. Then Figure 8a exhibits then if-then rules as:

$$
\begin{aligned}
& \text { Rule 1: if } x_{1} \text { is in } A_{1} \text { and } x_{2} \text { is in } B_{1} \\
& \text { Then } f_{1}=p_{1} x_{1}+q_{1} x_{2}+r_{1} \\
& \text { Rule 2: if } x_{1} \text { is in } A_{2} \text { and } x_{2} \text { is in } B_{2} \\
& \text { Then } f_{2}=p_{2} x_{1}+q_{2} x_{2}+r_{2}
\end{aligned}
$$

Where $p, q, r$ variables are utilized in the development and training of the final output of the TS fuzzy rules if-then.

The fuzzy sets A and B which are linguistic labes are described by the MFs of the input variables which shows low water levels (i.e $\mathrm{A}_{1}, \mathrm{~B}_{1}$ ) and also high water levels (i.e $\mathrm{A}_{2}, \mathrm{~B}_{2}$ ).

As previously stated, there are no standard techniques in choosing the type of MFs to give the most suitable performance in the described FIS. The best option is to adopt the ANFIS model which has been trained with the aid of the data of input-output for the optimization of the MFs; and the architecture of ANFIS is displayed in the Figure $8 \mathrm{~b}$ below. The nodes or neurons in the input layer are known as the input nodes while every other nodes are known as the adaptive nodes.

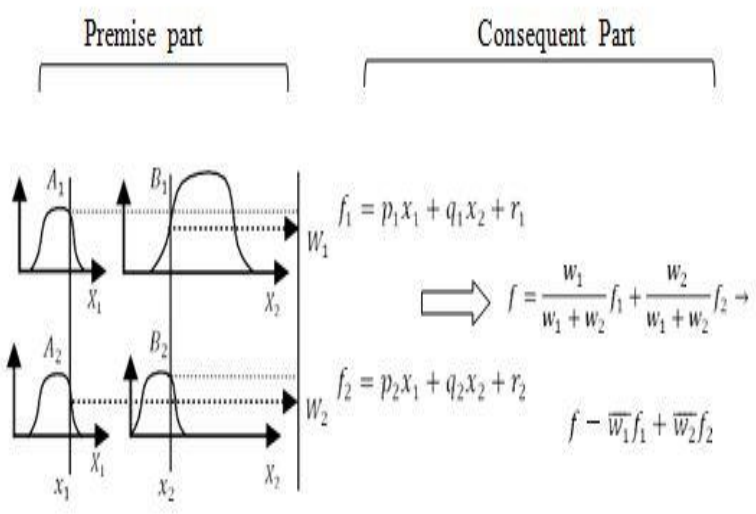

Figure 8a: Takagi-Sugeno fuzzy if-then rule and fuzzy reasoning mechanism (Aqil et al., 2007)

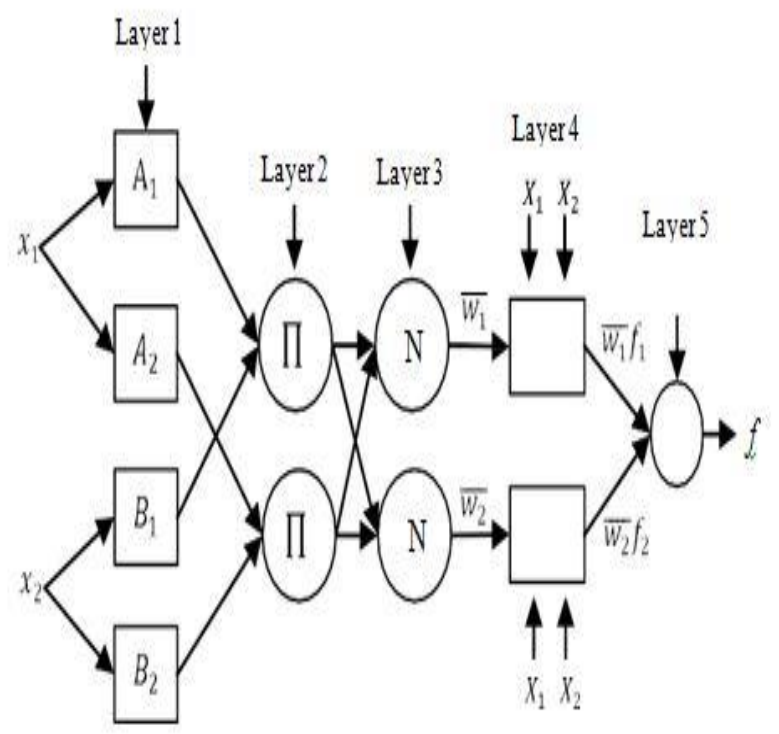

Figure 8b: Equivalent ANFIS architecture (Aqil et al., 2007) 
-

\section{Learning in ANFIS}

Learning in ANFIS models is attained by the identification of parameters that are able to adapt so as to reach the minimum error between actual output and the modelled output. The process which this is obtained in ANFIS is done by a hybrid learning algorithm which comprises the gradient descent (GD) as well as the least squares estimator (LSE)

Table 1: Two Pass Hybrid Learning Algorithm for ANFIS

\begin{tabular}{|c|c|c|}
\hline & Forward Pass & Backward Pass \\
\hline $\begin{array}{c}\text { Antecedent } \\
\text { Parameters }\end{array}$ & Fixed & GD \\
\hline $\begin{array}{c}\text { Consequent } \\
\text { Parameters }\end{array}$ & LSE & Fixed \\
\hline Signals & Node Outputs & Error Signals \\
\hline
\end{tabular}

(Rini et al., 2013)

The illustration as seen in the table above shows how different parameters are updated in the forward pass and how they are trained in the backward pass. The technique through which the premise parameter is identified is determined mainly through the Back Propagation algorithm embedded in ANN which has a limitation of most likely being trapped in local minima (AnandaKumar and Punithavalli, 2011). In the quest to improve performance and reduce error to the barest minimum it is necessary to examine an effective method of training in ANFIS for this purpose (Liu et al., 2013).

\section{- $\quad$ Methodology}

This review was done based on the following criteria which are:

1. Articles assessed: 30 different articles were assessed detailing applications of ANN, FL and ANFIS at describing different hydrologic activities.

2. Time frame: The articles assessed covered a time frame from the year 2007 to year 2018 which is time span of 11 years.

3. Activities: The articles were assessed based on vital hydrological activities such as streamflow, rainfallrunoff, groundwater modelling, water quality modelling, sediment load.

$\bullet$

\section{Application of AI in Streamflow}

Streamflow or discharge is an integral part of Water resource management. A reliable technique of forecasting flow of streams or rivers goes a long way in improving the operation of water management. The importance of streamflow has its relevance cutting across many aspects such as hydropower, irrigation, water supply, flood control, etc. And so it has become imperative to have reliable techniques in being able to forecast the flow of any river or stream thereby leading to a more efficient system of managing Water resources and its derivative activities.

In the past several methods have been used to forecast streamflow as demonstrated in Kang et al. (1993) where
Autoregressive moving average (ARMA) model was utilized in forecasting flow as well as comparing their performance with ANN model. Artificial Intelligence models have also been immensely used in forecasting flow in rivers such as the research work done by Panagoulia et al. (2017) devised a technical approach for the proficient selection of variables as input parameters in the ANN model. They adopted a step to step with multiple stages approach in order to attain the best combination of input variables for the model. Since it is a multiple stage process, several stages comprised different techniques in use for the purpose of evaluating the best combination of variables to be used as input parameters in the ANN model and subjected to indices of relevant statistics and ultimately optimizing the parameters under consideration. 15 different types of ANN models were formed with different time bound parameters of precipitation, temperature and flow as well as seasonality function sets as input variables in order to reliably forecast the flow of the river and based on their multistage approach, three different types of ANN models were selected from the 15 ANN models that were developed. Comparisons where done between the selected 3 ANN models, GA-ANN (ANN model optimized with GA) model, and the AR (Auto Regressive) Model; from the result it showed that one of the selected 3 ANN models performed best outperforming the other 2 ANN models and also the GA-ANN and AR models which illustrates that optimizing ANN with GA may not always be the best option in terms of reliability not to mention the effort and time required in carrying out optimization. Rezaei et al. (2015) used the ANN model for the forecasting of discharge of the Shoor Ghayen river and using the pruning of the network was done by the conventional trial and error method and the result of the prediction was good.

Kothari and Gharde (2015) where the ANN model and the Fuzzy Logic (FL) were both used to forecast the streamflow of the Savitiri River in India and the both results were compared; the data used were daily records of rainfall, evaporation, temperature and antecedent streamflow as the input variables while the streamflow as the output. Result showed that the FL model was very good when it used a single input variable and its accuracy decreased with increase in different variables which is in contrast with the ANN model whose accuracy increased with increase in the input variables. The best result for the FL model was compared with the best result of the ANN model and as shown in the result the ANN model was superior as the best result of the ANN models ( $\mathrm{R}=97 \%$ and RMSE $=113.08$ ) was juxataposed with the best result of the FL models $(\mathrm{R}=91 \%$ and $\mathrm{RMSE}=225.80)$. Cimen and Saplioglu (2007) also applied the fuzzy logic model to Koprucay river in Turkey such that the discharge data in Bekonak gauging station was simulated in order to be used to predict the discharge data at the Bolasan which is downstream of the river at about $15 \mathrm{~km}$ away. The results from the fuzzy logic model were quite good and reliable.

More so, Bisht and Jangid (2011) also used the ANN model as well as the Adaptive neuro-fuzzy Inference System model to predict the discharge of Godavari river, 
even though they both gave good results the ANFIS model outperformed the ANN model. The usage of AI models in streamflow modelling is gradually becoming more frequent as they are yielding reliable results in describing such hydrologic activity. Anusree and Vargheseb (2015) developed three different models of ANN, ANFIS and multiple nonlinear regression (MNLR) to simulate the streamflow of Karuvannur river basin in Thrissur district in India with data set of precipitation and discharge and the results and evaluation criteria used showed that the ANFIS model outperformed the ANN and the MNLR models.

\begin{tabular}{|c|c|c|c|c|}
\hline Research Topic & Model(s) & Input Variables & Output Variables & Reference \\
\hline $\begin{array}{l}\text { A multi-stage methodology for selecting } \\
\text { input variables in ANN forecasting of } \\
\text { river flows }\end{array}$ & ANN, AR, GA-ANN & $\begin{array}{l}\text { Precipitation, temperature, } \\
\text { seasonality function set and } \\
\text { discharge }\end{array}$ & Streamflow & $\begin{array}{l}\text { Panagoulia et al., } \\
2017\end{array}$ \\
\hline $\begin{array}{l}\text { River Flow Forecasting using artificial } \\
\text { neural network }\end{array}$ & ANN & $\begin{array}{l}\text { Discharge, precipitation and } \\
\text { tmeperature }\end{array}$ & Streamflow & Rezaei et al., 2015 \\
\hline $\begin{array}{l}\text { Application of ANN and fuzzy logic } \\
\text { algorithms for streamflow modelling of } \\
\text { Savitri catchment }\end{array}$ & ANN, FL & $\begin{array}{l}\text { Discharge, precipitation and } \\
\text { tmeperature }\end{array}$ & Streamflow & $\begin{array}{l}\text { Kothari and Gharde, } \\
2015\end{array}$ \\
\hline $\begin{array}{l}\text { Stream Flow Forecasting by Fuzzy Logic } \\
\text { Method }\end{array}$ & FL & Discharge & Streamflow & $\begin{array}{l}\text { Cimen and } \\
\text { Saplioglu, } 2007\end{array}$ \\
\hline $\begin{array}{l}\text { Discharge Modelling using Adaptive } \\
\text { Neuro - Fuzzy Inference System }\end{array}$ & ANFIS, ANN & River stage and Dsicharge & Streamflow & $\begin{array}{l}\text { Bisht and Jangid, } \\
2011\end{array}$ \\
\hline $\begin{array}{l}\text { Streamflow Prediction of Karuvannur } \\
\text { River Basin Using ANFIS, ANN and } \\
\text { MNLR Models }\end{array}$ & ANFIS, ANN, MNLR & Precipitation and Discharge & Streamflow & $\begin{array}{l}\text { Anusree and } \\
\text { Vargheseb, } 2015\end{array}$ \\
\hline
\end{tabular}

\section{Application of AI in Rainfall-Runoff}

The highly technical hydrological process is characterised by various phases. Storm water originating from precipitation transported through runoff to be collected by a catchment area which is distributed spatially, non-linear and varies with time. This complex phenomenon has been modelled using different simulation techniques, previously models used for the simulations of this phenomenon have been conceptually oriented which actually describes the process with aid of mathematical transformation whether linear or non-linear and are ambiguous from the perspective of calibration as well implementation.

However, some models constructed as a derivative of the linearized relationship of input and output through the complete avoidance or ignoring to take into account the physical laws governing complex rainfall-runoff process. This linear process-oriented model of rainfall-runoff is typified by the unit hydrograph; but the unit hydrograph neglects the nonlinear cases of the rainfall-runoff transformation.

Artificial Intelligence model is quite timely in adequately describing the rainfall-runoff complex dynamics and accounts for all the entirety of the process through relevant data and training or establishment of rules for taking into account all the dynamics and predicting reliably hence giving a more concrete prediction than the conceptual models. Several AI models have successfully been utilized in describing and predicting rainfall runoff process, Pan et al. (2008) adopted a Deterministic Linearized Recurrent Neural Network (DLRNN) which is a type of RNN in Taipei City in China and was utilized to simulate the rainfall runoff process and the compared with the conventional feed forward neural network and it showed RNN model performing better than FFN model. More so, Kalteh (2008) used the ANN model to simulate the rainfall runoff process in a watershed in Iran and it performed very well, however, because the ANN is a black box model he made use of three different techniques for the purpose of giving details to the mechanism and connection between rainfall and the runoff connection through the Garson's algorithm, randomization and Neural Interpretation Diagram (NID); moreover, the output was quite good.

Fuzzy logic also shows very good performance in simulating the rainfall runoff process, Casper et al. (2007) employed the Takagi-Sufeno-Kang technique in Fuzzy logic to simulate rainfall and soil moisture as input parameters in order to reliably forecast the runoff at the catchment outlet and the results were good and promising. Pawar et al. (2013) also used the fuzzy logic model in order to describe the rainfall runoff process of the Harsul Watershed in the Godavari basin in India; with rainfall only as input and runoff as the output and the results were very good.

ANFIS technique have also been previously used in the prediction of rainfall runoff process. Kuni and Mohandas (2014) made use of the ANN and ANFIS models to simulate the rainfall runoff process of Vamanapuram river basin and the results of both ANN and ANFIS were evaluated using the coefficient of determination and root mean square error. However, based on the evaluation tools used, it was deduced that both models performed well and reliably too but the ANN model performed slightly better than the ANFIS model. More so, Nawaz et al. (2016) also applied the ANFIS technique to the Semenyih river catchment and compared the result another model which is the Auto-Regressive model with eXogenous input (ARX) for describing and predicting the rainfall runoff process and the result showed that the ANFIS model outperformed the ARX. 


\begin{tabular}{|l|l|l|l|l|}
\hline Research Topic & Model(s) & Input Variables & $\begin{array}{l}\text { Output } \\
\text { Variables }\end{array}$ & Reference \\
\hline $\begin{array}{l}\text { Application of Recurrent Neural } \\
\text { Networks } \\
\text { to Rainfall-runoff Processes }\end{array}$ & ANN & Rainfall, Runoff & Runoff & Pan et al., 2008 \\
\hline $\begin{array}{l}\text { Rainfall-runoff modelling using } \\
\text { artificial neural networks } \\
\text { (ANNs): modelling and } \\
\text { understanding }\end{array}$ & ANN & $\begin{array}{l}\text { Rainfall, Runoff, } \\
\text { Temperature, Time }\end{array}$ & Runoff & Kalteh, 2008 \\
\hline $\begin{array}{l}\text { Fuzzy logic-based rainfall } \\
\text { runoff modelling using soil } \\
\text { moisture measurements to } \\
\text { represent system } \\
\text { state }\end{array}$ & FL & Soil moisture and Rainfall & Runoff & Casper et al., 2007 \\
\hline $\begin{array}{l}\text { Rainfall-runoff modelling using } \\
\text { fuzzy technique for a small } \\
\text { watershed. }\end{array}$ & FL & Rainfall & Runoff & Pawar et al., 2013 \\
\hline $\begin{array}{l}\text { Rainfall Runoff Modelling Using } \\
\text { ANN and ANFIS }\end{array}$ & ANFIS, ANN & Rainfall & Runoff & Kuni and Mohandas, \\
\hline $\begin{array}{l}\text { Event-based rainfall-runoff } \\
\text { modeling } \\
\text { using adaptive network-based } \\
\text { fuzzy } \\
\text { inference system }\end{array}$ & ANFIS, ARX & Rainfall, Runoff & Runoff & Nawaz et al., 2016 \\
\hline
\end{tabular}

\section{- $\quad$ Application of AI in Groundwater Modelling}

Groundwater is of immense importance in agriculture, industrial demands as well as domestic usage. Periodically, as the groundwater level changes, a reliable forecasting model is needed for the sake of sustainability. The process of being able to attain confident prediction of groundwater level of a watershed has a pivotal role in groundwater resources management, more importantly in semi-arid regions where supply of groundwater is highly needed. Aziz and Wong (1992) used normalized data of drawdown gotten via pumping tests from ANN technique to get the values of aquifer parameter; this process is known as the reverse problem in groundwater in hydrology.

Ehteshami et al. (2016) used two different types of ANN models namely: the Radial basis function neural network (RBFNN) and the back propagation neural network (BPNN) to both simulate and predict the amount of nitrate contamination in groundwater. Although both RBFNN and BPNN both showed approximate prediction results which were very satisfactory but the RBFNN result was slightly better. This is supported by the established fact in the work of Moradkani et al. (2004) implying the advantage of RBFNN over conventional ANN models in that they converge faster, have much smaller errors in extrapolation. ANN is such an immense technique in groundwater for different purposes as also Nasr and Zahran (2014) adopted the ANN model in order to predict the salinity of groundwater with $\mathrm{pH}$ of the groundwater as the only input variable and the result from the model is very much acceptable.

Fuzzy logic is also very resourceful in groundwater analysis as seen in the work of Rahimi and Mokarram (2012) where FL model was used to describe and ultimately assess groundwater quality in the area of prediction Sodium Adsorption Ration (SAR) through various input parameters with a very reliable result. More so, FL has shown promising results in assessing water quality for drinking purpose from groundwater assessment as seen by Gorai et al. (2016) who used several parameters as input variables to be able to ascertain water quality index of groundwater and to predict if the groundwater is fit for drinking.

ANFIS as a very resource AI model is also very much utilized in groundwater modelling as well in the for several groundwater process analysis. Umamaheswani and Kalamani (2014) utilized very important input parameters such as Groundwater recharge, Groundwater discharge and antecedent groundwater table to be able to predict the level of groundwater and the outcome was good and resourceful in monitoring the groundwater resources. In another research work by Bisht et al. (2009) the groundwater water table assessment and prediction was done by the models of FL and ANFIS and compared to ascertain which model is better in groundwater process analysis in Budaun district in Inida and with the two models performing very well; however the ANFIS model proved to give better results than the FL model. 


\begin{tabular}{|c|c|c|c|c|}
\hline Research Topic & Model(s) & Input Variables & Output Variables & Reference \\
\hline $\begin{array}{l}\text { Simulation of nitrate } \\
\text { contamination in groundwater } \\
\text { using artificial neural } \\
\text { networks }\end{array}$ & ANN (RBFNN, BPNN) & $\begin{array}{l}\text { Nitrite in groundwater, soil } \\
\text { organic matter content, soil } \\
\text { nitrogen content, } \mathrm{pH}\end{array}$ & Nitrate in groundwater & Ehteshami et al., 2016 \\
\hline $\begin{array}{l}\text { Using of } \mathrm{pH} \text { as a tool to } \\
\text { predict salinity of } \\
\text { groundwater for irrigation } \\
\text { purpose using artificial neural } \\
\text { network }\end{array}$ & ANN & $\mathrm{pH}$ & Salinity & Nasr and Zahran, 2014 \\
\hline $\begin{array}{l}\text { Assessing the groundwater } \\
\text { quality by applying fuzzy } \\
\text { logic in GIS } \\
\text { environment- A case study in } \\
\text { Southwest Iran }\end{array}$ & FL & $\begin{array}{l}\text { Electrical Conductivity (EC), } \\
\mathrm{Mg}, \mathrm{Na}, \mathrm{Ca}\end{array}$ & SAR & $\begin{array}{l}\text { Rahimi and Mokarram, } \\
2012\end{array}$ \\
\hline $\begin{array}{l}\text { Prediction of ground water } \\
\text { quality index to assess } \\
\text { suitability for drinking } \\
\text { purposes using fuzzy rule- } \\
\text { based approach }\end{array}$ & FL & $\begin{array}{l}\text { Alkalinity, hardness, } \\
\text { Dissolved solids, pH, Ca, } \\
\text { Mg, Fe, As, Sulphate, } \\
\text { Nitrates, Fluoride }\end{array}$ & $\begin{array}{l}\text { Fuzzy water quality } \\
\text { index (FWQI) }\end{array}$ & Gorai et al., 2016 \\
\hline $\begin{array}{l}\text { Fuzzy Logic Model for the } \\
\text { Prediction of } \\
\text { Groundwater Level in } \\
\text { Amaravathi River Minor } \\
\text { Basin }\end{array}$ & ANFIS & $\begin{array}{l}\text { Groundwater recharge, } \\
\text { groundwater discharge, } \\
\text { previous groundwater table, }\end{array}$ & $\begin{array}{l}\text { Present groundwater } \\
\text { table fluctuation }\end{array}$ & $\begin{array}{l}\text { Umamaheswani and } \\
\text { Kalamani, } 2014\end{array}$ \\
\hline $\begin{array}{l}\text { Simulation of water table } \\
\text { elevation fluctuation using } \\
\text { fuzzy-logic and ANFIS }\end{array}$ & FL, ANFIS & $\begin{array}{l}\text { Groundwater recharge, } \\
\text { Groundwater discharge, } \\
\text { previous groundwater table }\end{array}$ & $\begin{array}{l}\text { Present groundwater } \\
\text { table elevation }\end{array}$ & Bisht et al. 2009 \\
\hline
\end{tabular}

\section{- $\quad$ Application of AI in Water Quality Modelling}

Parameters such as chemical, biological and physical attributes are used in the characterization of water quality. Water quality is majorly affected by discharge, contaminant level, water levels, mode of transportation, prior conditions. More so, water quality does have a great influence on all uses of water regardless of the purpose. Uses of water such as swimming, industries, irrigation, domestic usage, livestock, aesthetics and recreation, etc are all greatly affected by prior conditions of the water body such chemical, physical and even microbiological features (Heathcote, 1998).

There is interconnectivity between parameters that define water quality, so it has become imperative to assess whether there are patterns to illustrate the tendency of variables to be predicted. Models which can forecast such variables are of great interest to environmentalists and ecologists as well because such models will be used to predict levels of pollution in water and will be able to technical steps ahead as precaution. A process-based model has very high requirements such as lots input data and parameters of model which most of the time are actually unknown whereas data-driven models are efficient substitutes to former; based on the fact that they only require few input variables compared to process-based techniques.

Kalin and Isik (2010) utilized ANN technique on assessing water quality in 18 watersheds in Georgia, USA, the FFN of ANN was adopted with back propagation training algorithm for the purpose some water quality parameters such as: $\mathrm{Cl} \mathrm{SO}_{4}, \mathrm{Na}, \mathrm{K}$ and DOC with good results as output.

Seo et al. (2016) also used the ANN model to simulate previous and current parameters of water quality in order forecast a step ahead water quality parameters of Cheongpyeong dam and the results of different water quality such as Total Nitrogen (TN), Total Phosphorus (TP), Electrical Conductivity (EC), Turbidity, Temperature, Dissolved Oxygen (DO), pH, Chlorophyll while they all showed very good results only the turbidity showed a little less accurate result compared to the others. However, the turbidity forecast is still good.

Bai et al. (2009) utilized fuzzy logic model to simulate Fuzzy Water Quality Index (FQWI) of the Semenyih river in Malaysia, and the results were compared with the actual Water Quality Index (WQI) which comprise biochemical oxygen demand (BOD), chemical oxygen demand (COD), Suspended Solids (SS), ammoniacal nitrogen (AN), $\mathrm{pH}$ and Dissolved Oxygen (DO) which demonstrated a very promising result and shows the FL model is efficient in assessing water quality. Semiromi et al. (2011) also explored FL model to assess the WQI of Karoon river in Iran and the WQI of the river was compare with the actual WQI of the Iranian Environment Protection Agency (IEPA) and the results were quite satisfactory and resourceful.

ANFIS models have also been known to be immensely resourceful in water quality assessment in rivers and other water bodies. Sonmez et al. (2018) used the ANFIS model to simulate and predict the concentration of Cadmium in Filyos river and the result according to the evaluation technique was very good and suitable. Khadr and Elshemy (2017) developed two ANFIS models to predict the quantity of TP and TN in Manzala Lake in Egypt through several other parameters such as EC, TSS, TDS, DO, Turbidity, Temperature $\mathrm{pH}$, dicscharge and the outputs for $\mathrm{TP}$ and TN were both very reliable. 


\begin{tabular}{|c|c|c|c|c|}
\hline Research Topic & Model(s) & Input Variables & Output Variables & Reference \\
\hline $\begin{array}{l}\text { Prediction of Water Quality } \\
\text { Parameters Using An Artificial } \\
\text { Neural Networks Model }\end{array}$ & ANN & $\begin{array}{l}\text { Percentage of land use } \\
\text { type, temperature effect } \\
\text { and stream discharge }\end{array}$ & $\begin{array}{l}\mathrm{Cl} \mathrm{SO}_{4}, \mathrm{Na}, \mathrm{K} \text { and } \\
\text { DOC }\end{array}$ & Kalin and Isik, 2010 \\
\hline $\begin{array}{l}\text { Forecasting Water Quality } \\
\text { Parameters by ANN Model using } \\
\text { Preprocessing Technique at The } \\
\text { Downstream of Cheongpyeong } \\
\text { Dam }\end{array}$ & ANN & $\begin{array}{l}\text { Previous and Current } \\
\text { data of TN, TP, EC, } \\
\text { Turbidity, Temperature, } \\
\text { DO, pH, Chlorophyll }\end{array}$ & $\begin{array}{l}\text { Future data of TN, TP, } \\
\text { EC, Turbidity, } \\
\text { Temperature, DO, pH, } \\
\text { Chlorophyll }\end{array}$ & Seo et al., 2016 \\
\hline $\begin{array}{l}\text { Fuzzy Logic Water Quality } \\
\text { Index and Importance of Water } \\
\text { Quality Parameters }\end{array}$ & FL & $\begin{array}{l}\text { BOD, DO,COD, SS, } \\
\text { pH, AN }\end{array}$ & FWQI & Bai et al., 2009 \\
\hline $\begin{array}{l}\text { Water quality index development } \\
\text { using fuzzy logic: A case study } \\
\text { of the Karoon River of Iran }\end{array}$ & FL & $\begin{array}{l}\text { TDS, Total Coliform, } \\
\text { Turbidity, DO, pH, } \\
\text { Nitrate. }\end{array}$ & FWQI & Semiromi et al., 2011 \\
\hline $\begin{array}{l}\text { An Adaptive Neuro-Fuzzy } \\
\text { Inference System (ANFIS) to } \\
\text { Predict of Cadmium (Cd) } \\
\text { Concentrations in the Filyos } \\
\text { River, Turkey }\end{array}$ & ANFIS & $\begin{array}{l}\mathrm{Fe}, \mathrm{Cu}, \mathrm{Mn}, \mathrm{Zn}, \mathrm{Ni} \text { and } \\
\mathrm{Cr}\end{array}$ & $\mathrm{Cd}$ & Sonmez et al., 2018 \\
\hline $\begin{array}{l}\text { Data-driven modeling for water } \\
\text { quality prediction case study: } \\
\text { The drains system associated } \\
\text { with Manzala Lake, Egypt }\end{array}$ & ANFIS & $\begin{array}{l}\text { EC, TSS, TDS, DO, } \\
\text { Turbidity, Temperature } \\
\text { pH, dicscharge }\end{array}$ & TP and TN & $\begin{array}{l}\text { Khadr and Elshemy, } \\
2017\end{array}$ \\
\hline
\end{tabular}

Application of AI in Sediment Load Prediction

The effect of sediment load in rivers cannot be overemphasized especially in dams where trapping of sediment is very common, and these sediment loads do cause very harmful effect both to the aquatic ecosystem as well as the surrounding environment such as tendency to cause flood, transportation of contaminants in rivers, reducing the storage capacity of the reservoir, reduction of light penetration in the river, etc. It is therefore of great interest to be able to be able to reliably estimate the sediment load in a river to be able to plan and manage water resources efficiently. AI models have been of immense usage in predicting sediment loads in rivers and hence tremendously improved water resources management.

Melesse et al. (2007) developed the ANN model to able to be estimate suspended sediment load in three rivers in the USA for the purpose of having a reliable water source for Irrigation water supply and the results for using ANN to predict suspended sediment load were quite very satisfactory; results for daily sediment load prediction at Mississippi ( $\mathrm{R}^{2}$ for the following models: $\mathrm{ANN}=0.96$, MLR=0.76, MNLR0.97, ARIMA=0.98); at Missouri $\left(\mathrm{R}^{2}\right.$ for the following models: $\mathrm{ANN}=0.97, \quad \mathrm{MLR}=0.61$, MNLR=0.95, ARIMA=0.92); at Rio Grande $\left(\mathrm{R}^{2}\right.$ for the following models: $\mathrm{ANN}=0.65, \mathrm{MLR}=0.52, \mathrm{MNLR}=0.58$, ARIMA=0.55). Shabani and Shabani (2012) used the ANN model to simulate Sediment yield in Kharestan Watershed Iran and compared the result with the conventional Sediment Rating Curve (SRC) and the results showed ANN outperforming the SRC $\left(\mathrm{R}^{2}\right.$ for $\mathrm{ANN}=0.98$ and $\mathrm{SRC}=0.74)$.

Fuzzy logic is also a very resourceful technique in estimating suspended sediment load in rivers and very promising results have been derived from the utilization of the FL approach. Nivesh et al. (2018) applied FL model in the prediction of suspended sediment load and the results were compared with prediction done by the Sediment Rating Curve (SRC) model as well as a Multi-linear
Regression (MLR) model and the results showed that the FL model outperformed the other two models while the conventional SRC model has the least performance of the three models. Unes et al. (2015) also adopted the FL technique to estimate sediment concentration and compared the result also with the conventional SRC model as well; the result showed a very good performance of the FL model over the SRC model despite that the input variable used was only the discharge; it goes to show that the FL model is very much satisfactory in estimating sediment load.

ANFIS models have also proven to be of immense importance in the description and estimation of suspended sediment load for various rivers and hydrologic processes. Firat and Gungor (2010) used the ANFIS approach to reliably estimate monthly suspended sediment load in a river using the discharge and antecedent discharge data input to forecast suspended sediment load and the results obtained were typically compared with the forecast result of ANN and MLR models and from the results obtained the ANFIS performed best of the three models followed closely by the ANN model. As seen in this review ANFIS model have been commonly seen to outperform other models but this is not always the case depending on the type of data available for simulation, it is very much possible for other models to perform better than the ANFIS model. Mohamed and Shah (2018) made use of several models such as ANFIS, ANN, SRC, MLR and the Simple Linear Regression (SLR) to estimate suspended sediment load in a river were different input selection was done for the models ranging from discharge, temperature and Conductivity. It is however seen that the ANN model using three inputs of Discharge, Temperature and Conductivity performed best before the ANFIS model of similar input parameters while the least performing model was the SRC model with single input as discharge with a common prediction of the suspended sediment load. Notwithstanding the ANFIS model gave satisfactory result as well. 


\begin{tabular}{|c|c|c|c|c|}
\hline Research Topic & Model(s) & Input Variables & Output Variables & Reference \\
\hline $\begin{array}{l}\text { Suspended sediment load } \\
\text { prediction of river systems: An } \\
\text { artificial neural network approach }\end{array}$ & $\begin{array}{l}\text { ANN, MLR, } \\
\text { MNLR, } \\
\text { ARIMA }\end{array}$ & $\begin{array}{l}\text { Precipitation }(\mathrm{P}) \text {, } \\
\text { Discharge }(\mathrm{Q}) \text {, } \\
\text { antecedent dats of } \\
\text { discharge and } \\
\text { Sediement load } \\
\end{array}$ & Sediment load & Melesse et al., 2007 \\
\hline $\begin{array}{l}\text { Estimation of Daily Suspended } \\
\text { Sediment Yield Using Artificial } \\
\text { Neural Network and } \\
\text { Sediment Rating Curve in } \\
\text { Kharestan Watershed, Iran } \\
\end{array}$ & ANN, SRC & Water discharge & Sediment discharge & $\begin{array}{l}\text { Shabani and Shabani, } \\
2012\end{array}$ \\
\hline $\begin{array}{l}\text { Application of Fuzzy Logic and } \\
\text { Statistical Approaches for } \\
\text { Estimation of Suspended } \\
\text { Sediment Concentration }\end{array}$ & $\begin{array}{l}\text { FL, } \\
\text { MLR }\end{array}$ & Rainfall, Discharge & Sediment load & Nivesh et al., 2018 \\
\hline $\begin{array}{l}\text { Suspended sediment estimation of } \\
\text { skunk river in USA using fuzzy } \\
\text { logic model }\end{array}$ & FL, SRC & Discharge & $\begin{array}{l}\text { Suspended } \\
\text { concentration }\end{array}$ & Unes et al., 2015 \\
\hline $\begin{array}{l}\text { Monthly total sediment } \\
\text { forecasting using adaptive neuro } \\
\text { fuzzy } \\
\text { inference system }\end{array}$ & $\begin{array}{l}\text { ANFIS, } \\
\text { ANN, MLR }\end{array}$ & $\begin{array}{l}\text { Dicharge and } \\
\text { Anteccedent discharge }\end{array}$ & $\begin{array}{ll}\text { Suspended } & \text { Sediment } \\
\text { load } & \end{array}$ & $\begin{array}{l}\text { Firant and Gungor, } \\
2010\end{array}$ \\
\hline $\begin{array}{l}\text { Suspended Sediment } \\
\text { Concentration Modeling Using } \\
\text { Conventional and Machine } \\
\text { Learning Approaches in the } \\
\text { Thames River, London Ontario }\end{array}$ & $\begin{array}{l}\text { ANFIS, } \\
\text { ANN, SRC, } \\
\text { SLR, MLR }\end{array}$ & $\begin{array}{l}\text { Discharge, } \\
\text { Temperature, } \\
\text { Conductivity }\end{array}$ & $\begin{array}{ll}\text { Suspended } & \text { Sediment } \\
\text { load } & \end{array}$ & $\begin{array}{l}\text { Mohamed and Shah, } \\
2018\end{array}$ \\
\hline
\end{tabular}

\section{Selection of inputs and Division of data in Model \\ development}

While developing an ANFIS model, the first thing to be done is the determination of the input variables. Although there are no standards in the selection of input variables in most artificial intelligence (AI) models which thus make the process of input variable selection of great contention while developing models and forecasting as well (Zounemat-Kermani and Teshnehlab, 2008). When input selection of a model input is accurate, it does have a have a positive effect on the architecture of the model, its speed of processing data, amount of "if-then" rules and the desired output. ANFIS and ANN have the unique feature of being able to establish the pivotal model inputs, any attempt to present numerous inputs to the network will consequently increase the network size as well as the number of rules; which will subsequently decrease the processing speed (Nayak et al., 2005). It is applicable when there is no previous knowledge of the system being considered. However, an approach has been suggested which is embedded in "autocorrelation $(A C F)$ " and also "partial autocorrelation function (PACF)" to aid in the selection of inputs in ANFIS modelling (Nayak et al., 2004).

The second aspect is the classification of data into separate groups for the purpose of training and which will subsequently lead to testing of the model. The subset of the training phase is used in order to optimize the model while the subset of the testing phase is utilised to scrutinize the performance and subsequently the generalization of the model (Mehta and Jain, 2009).

\section{- $\quad$ Research Gaps}

The following were noticed as a lacuna in the implementation of the several AI models in the different articles:

1. Lack of proper analysis in detecting the amount of noise in data which tends to discredit the efficacy of the models, hence no clarity in the choosing the best combination of parameters as inputs for the models.

2. Some articles did not state the quantity of the data set employed, the portion for training and testing alike.

\section{DISCUSSION}

From the several hydrological activities described and the different techniques used, a lot of interesting results showed that no AI model is totally superior to the other as they have all showed better predictions in different scenarios and the quality of data used. Generally, it is perceived that ANFIS is a better model to ANN and FL being that it is a hybrid model of the two and so it is expected to be better which is the case more often (Tao et al., 2016). However, it is not always so, Kuni and Mohandas (2014) employed both ANN and ANFIS in predicting rainfall-runoff which showed ANN performing better even though both gave satisfactory results. More so, Mohamed and Shah (2018) also adopted several models including ANN, ANFIS, SLR, SRC and MLR to predict suspended sediment load and ANN (RMSE= 3.720) model performed better than the ANFIS (RMSE=7.082).

Although AI models have a proven track record of predicting acceptably but there has been cases of enhancement of their predictability by optimization in order to further improve their results; however, this has been demystified in the work of Panagoulia et al. (2017) as it is seen that several ANN models were compared with a 
GA-ANN optimized model and one of the ANN model outperformed the GA-ANN to show that optimization is not always the best solution but can produce result above the benchmark.

From the several articles reviewed, it showed that AI models outperformed other type of models such as SLR, MLR, SRC, ARMA, ARX in comparison of their results and this is suggestive of their superiority and being able to replace these conventional models.

\section{CONCLUSION}

Over past decades, the use of AI techniques is becoming more popular and more readily in use especially in the area of hydrological modelling. ANN however seem to be the most common AI model being used in Water resources management, but more recently have seen other models being resourceful and utilized increasingly such as the FL and ANFIS approach.

From this review done in assessing the performance of several AI models in different scenarios of hydrological process, it is seen that the AI models outperformed other models that were in use prior to the introduction of the AI models to predict hydrological process under consideration and this is a very promising dimension in Water Resources management for better analysis and improved management system, AI models have brought about a substantial attribute to various research works done and even works yet to be done in the future. AI models are there reliable tools in estimation in Water Resources management. Based on the results stated in the several articles reviewed, the outperformance of the AI models over conventional models and the satisfactory results of the AI models based on performance statistical tools, has deduced that AI models are very reliable and can readily replace the conventional models in use for predicting hydrological activities.

\section{REFERENCES}

[1] Alagha, J. S., Said, M. A. M., \& Mogheir, Y. (2012). Artificial intelligence based modelling of hydrological processes.

[2] AnandaKumar, K., \& Punithavalli, M. (2011). Efficient cancer classification using fast adaptive neuro-fuzzy inference system (FANFIS) based on statistical techniques. IJACSA) International Journal of Advanced Computer Science and Applications, Special Issue on Artificial Intelligence, , 132-137.

[3] Anusree, K., \& Varghese, K. O. (2016). Streamflow prediction of karuvannur river basin using ANFIS, ANN and MNLR models.Procedia Technology, 24, 101-108.

[4] Aqil, M., Kita, I., Yano, A., \& Nishiyama, S. (2007). Analysis and prediction of flow from local source in a river basin using a neuro-fuzzy modeling tool. Journal of Environmental Management, 85(1), 215-223.

[5] Article, M. Rainfall runoff modelling using ANN and ANFIS

[6] ArticleI, J E M S J. Rainfall-runoff modelling using fuzzy technique for a small watershed.

[7] ASCE Task Committee on Application of Artificial Neural Networks in Hydrology. (2000). Artificial neural networks in hydrology. I: Preliminary concepts. Journal of Hydrologic Engineering, 5(2), 115-123.

[8] Aziz, A. R. A., \& Wong, K. V. (1992). A neural-network approach to the determination of aquifer parameters. Groundwater, 30(2), 164-166.

[9] Babuška, R., \& Verbruggen, H. (2003). Neuro-fuzzy methods for nonlinear system identification. Annual Reviews in Control, 27(1), 73-85
[10] Bai, V., Bouwmeester, R., \& Mohan, S. (2009). Fuzzy logic water quality index and importance of water quality parameters. Air Soil \& Water Research, (2)

[11] Bardossy, A., \& Duckstein, L. (1995). Fuzzy rule-based modeling with applications to geophysical, biological, and engineering systems.

[12] Basheer, I. A., \& Hajmeer, M. (2000). Artificial neural networks: Fundamentals, computing, design, and application. Journal of Microbiological Methods, 43(1), 3-31.

[13] Besaw, L. E., \& Rizzo, D. M. (2007). Stochastic simulation and spatial estimation with multiple data types using artificial neural networks. Water Resources Research, 43(11)

[14] Bisht, D., Raju, M., \& Joshi, M. (2009). Simulation of water table elevation fluctuation using fuzzy-logic and ANFIS. Computer Modelling and New Technologies, 13(2), 16-23.

[15] Bisht, D. C., \& Jangid, A. (2011). Discharge modelling using adaptive neuro-fuzzy inference system. International Journal of Advanced Science and Technology, 31(1), 99-114.

[16] Casper, M., Gemmar, P., Gronz, O., Johst, M., \& Stueber, M. (2007). Fuzzy logic-based rainfall-runoff modelling using soil moisture measurements to represent system state. Hydrological Sciences Journal, 52(3), 478-490.

[17] Chang, F., \& Chang, Y. (2006). Adaptive neuro-fuzzy inference system for prediction of water level in reservoir. Advances in Water Resources, 29(1), 1-10.

[18] Chen, S. H., Jakeman, A. J., \& Norton, J. P. (2008). Artificial intelligence techniques: An introduction to their use for modelling environmental systems. Mathematics and Computers in Simulation, 78(2-3), 379-400.

[19] Chen, Y., \& Chang, F. (2009). Evolutionary artificial neural networks for hydrological systems forecasting. Journal of Hydrology, 367(1-2), 125-137.

[20] Cimen, M., \& SAPLIOĞLU, K. (2007). (2007). Strem flow forecasting by fuzzy logic method. Paper presented at the International Congress on River Basin Management, 612-620.

[21] Conference Paper, D. A critical review of hydrological models

[22] Coppola, E. A., Rana, A. J., Poulton, M. M., Szidarovszky, F., \& Uhl, V. W. (2005). A neural network model for predicting aquifer water level elevations. Groundwater, 43(2), 231-241.

[23] Daliakopoulos, I. N., Coulibaly, P., \& Tsanis, I. K. (2005). Groundwater level forecasting using artificial neural networks. Journal of Hydrology, 309(1-4), 229-240.

[24] Džeroski, S., Grbović, J., Walley, W. J., \& Kompare, B. (1997). Using machine learning techniques in the construction of models. II. data analysis with rule induction. Ecological Modelling, 95(1), 95-111.

[25] Ehteshami, M., Farahani, N. D., \& Tavassoli, S. (2016). Simulation of nitrate contamination in groundwater using artificial neural networks. Modeling Earth Systems and Environment, 2(1), 28.

[26] El Tabach, E., Lancelot, L., Shahrour, I., \& Najjar, Y. (2007). Use of artificial neural network simulation metamodelling to assess groundwater contamination in a road project. Mathematical and Computer Modelling, 45(7-8), 766-776

[27] Firat, M., \& G ng rr, M. (2007). River flow estimation using adaptive neuro fuzzy inference system. Mathematics and Computers in Simulation, 75(3-4), 87-96.

[28] Firat, M., \& Güngör, M. (2010). Monthly total sediment forecasting using adaptive neuro fuzzy inference system. Stochastic Environmental Research and Risk Assessment, 24(2), 259-270.

[29] Galavi, H., \& Shui, L. T. (2012a). Neuro-fuzzy modelling and forecasting in water resources. Scientific Research and Essays, 7(24), 2112-2121.

[30] Galavi, H., \& Shui, L. T. (2012b). Neuro-fuzzy modelling and forecasting in water resources. Scientific Research and Essays, 7(24), 2112-2121.

[31] Gorai, A. K., Hasni, S. A., \& Iqbal, J. (2016). Prediction of ground water quality index to assess suitability for drinking purposes using fuzzy rule-based approach. Applied Water Science, 6(4), 393-405.

[32] Heathcote, I. W. (1998). Integrated watershed management: Principles and practices. john wiley\& sons. Inc.New York,

[33] Jain, A. K., Mao, J., \& Mohiuddin, K. M. (1996). Artificial neural networks: A tutorial. Computer, 29(3), 31-44. 
[34] Jang, J. (1993). ANFIS: Adaptive-network-based fuzzy inference system. IEEE Transactions on Systems, Man, and Cybernetics, 23(3), 665-685.

[35] Jang, J. R., Sun, C., \& Mizutani, E. (1997). Neuro-fuzzy and soft computing-a computational approach to learning and machine intelligence [book review]. IEEE Transactions on Automatic Control, 42(10), 1482-1484.

[36] Javadi, A. A., \& Al-Najjar, M. M. (2007). Finite element modeling of contaminant transport in soils including the effect of chemical reactions. Journal of Hazardous Materials, 143(3), 690701

[37] Kalin, L., \& Isik, S. (2010). (2010). Prediction of water quality parameters using an artificial neural networks model. Paper presented at the World Environmental and Water Resources Congress 2010: Challenges of Change, 3145-3153.

[38] Kalteh, A. M. (2008). Rainfall-runoff modelling using artificial neural networks (ANNs): Modelling and understanding. Caspian Journal of Environmental Sciences, 6(1), 53-58.

[39] Kang, W. (1993). W. kang, HL stormer, LN pfeiffer, KW baldwin, and KW west, phys. rev. lett. 71, 3850 (1993). Phys.Rev.Lett., 71, 3850.

[40] Khadr, M., \& Elshemy, M. (2017). Data-driven modeling for water quality prediction case study: The drains system associated with manzala lake, egypt. Ain Shams Engineering Journal, 8(4), 549-557.

[41] Kingston, G. B., Dandy, G. C., \& Maier, H. R. (2008). Review of artificial intelligence techniques and their applications to hydrological modeling and water resources management part 2optimization. Water Resources Research Progress, , 67-99.

[42] Kothari, M., \& Gharde, K. D. (2015). Application of ANN and fuzzy logic algorithms for streamflow modelling of savitri catchment. Journal of Earth System Science, 124(5), 933-943.

[43] Krishna, B., Satyaji Rao, Y. R., \& Vijaya, T. (2008). Modelling groundwater levels in an urban coastal aquifer using artificial neural networks. Hydrological Processes, 22(8), 1180-1188.

[44] Lin, G., \& Chen, G. (2006). An improved neural network approach to the determination of aquifer parameters. Journal of Hydrology, 316(1-4), 281-289.

[45] Liu, P., Leng, W., \& Fang, W. (2013). Training ANFIS model with an improved quantum-behaved particle swarm optimization algorithm. Mathematical Problems in Engineering, 2013

[46] Maier, H. R., \& Dandy, G. C. (2001). Neural network based modelling of environmental variables: A systematic approach.Mathematical and Computer Modelling, 33(6-7), 669682.

[47] Makkar, R. (2018). Application of fuzzy logic: A literature review.

[48] McCuen, R. H. (2016). Hydrologic analysis and design Prentice Hall.

[49] Mehta, R., \& Jain, S. K. (2009). Optimal operation of a multipurpose reservoir using neuro-fuzzy technique. Water Resources Management, 23(3), 509-529.

[50] Melesse, A. M., Ahmad, S., McClain, M. E., Wang, X., \& Lim, Y. H. (2011). Suspended sediment load prediction of river systems: An artificial neural network approach. Agricultural Water Management, 98(5), 855-866.

[51] Michalewicz, Z., \& Fogel, D. B. (2013). How to solve it: Modern heuristics Springer Science \& Business Media.

[52] Mohamed, I., \& Shah, I. (2018). Suspended sediment concentration modeling using conventional and machine learning approaches in the thames river, london ontario. Journal of Water Management Modeling,

[53] Moradkhani, H., Hsu, K., Gupta, H. V., \& Sorooshian, S. (2004). Improved streamflow forecasting using self-organizing radial basis function artificial neural networks. Journal of Hydrology, 295(1-4), 246-262.

[54] Nasr, M., \& Zahran, H. F. (2014). Using of pH as a tool to predict salinity of groundwater for irrigation purpose using artificial neural network. The Egyptian Journal of Aquatic Research, 40(2), 111-115.

[55] Nawaz, N., Harun, S., Talei, A., \& Chang, T. K. (2016). Eventbased rainfall-runoff modeling using adaptive network-based fuzzy inference system. Jurnal Teknologi, 78(9-4)
[56] Nayak, P. C., Sudheer, K. P., Rangan, D. M., \& Ramasastri, K. S. (2004). A neuro-fuzzy computing technique for modeling hydrological time series. Journal of Hydrology, 291(1-2), 52-66.

[57] Negnevitsky, M., \& Intelligence, A. (2005). A guide to intelligent systems. Artificial Intelligence, 2nd Edition, Pearson Education,

[58] Nivesh, S., Kumar, P., Sawant, P., \& Verma, R. (2018). Application of fuzzy logic and statistical approaches for estimation of suspended sediment concentration. Int.J.Curr.Microbiol.App.Sci, 7(2), 3716-3733.

[59] Palani, S., Liong, S., \& Tkalich, P. (2008). An ANN application for water quality forecasting. Marine Pollution Bulletin, 56(9), 1586-1597.

[60] Pan, T., Wang, R., Lai, J., \& Yu, H. (2008). Application of recurrent neural networks to rainfall-runoff processes. Recurrent neural networks () IntechOpen.

[61] Panagoulia, D., Tsekouras, G. J., \& Kousiouris, G. (2017). A multi-stage methodology for selecting input variables in ANN forecasting of river flows. Glob.Nest J, 19, 49-57.

[62] Priddy, K. L., \& Keller, P. E. (2005). Artificial neural networks. An introduction SPIE press.

[63] Rahimi, D., \& Mokarram, M. (2012). Assessing the groundwater quality by applying fuzzy logic in GIS environment-A case study in southwest iran. International Journal of Environmental Sciences, 2(3), 1798-1806.

[64] Rezaei, M., Akbari Motlaq, A. A., Rezvani Mahmouei, A., \& Hojjatollah Mousavi, S. (2015). River flow forecasting using artificial neural network (shoor ghaen). Ciência E Natura, 37(6-1)

[65] Rini, D. P., Shamsuddin, S. M., \& Yuhaniz, S. S. (2013). Balanced the trade-offs problem of anfis using particle swarm optimisation. TELKOMNIKA Telecommunication, Computing, Electronics and Control, 11(3), 611-616.

[66] Rusell, S., \& Norvig, P. (2003). Artificial intelligence: A modern approach. Pretice Hall Series in Artificial Intelligence, 1

[67] Semiromi, F. B., Hassani, A. H., Torabian, A., Karbassi, A. R., \& Lotfi, F. H. (2011). Water quality index development using fuzzy logic: A case study of the karoon river of iran. African Journal of Biotechnology, 10(50), 10125-10133.

[68] Shabani, M., \& Shabani, N. (2012). Estimation of daily suspended sediment yield using artificial neural network and sediment rating curve in kharestan watershed, iran. Australian Journal of Basic and Applied Sciences, 6(12), 157-164.

[69] Sibanda, W., \& Pretorius, P. (2012). Artificial neural networks-a review of applications of neural networks in the modeling of hiv epidemic. International Journal of Computer Applications, 44(16), 1-9.

[70] Singh, R. M., \& Datta, B. (2007). Artificial neural network modeling for identification of unknown pollution sources in groundwater with partially missing concentration observation data. Water Resources Management, 21(3), 557-572.

[71] Sonmez, A. Y., Kale, S., Ozdemir, R. C., \& Kadak, A. E. (2018) An adaptive neuro-fuzzy inference system (ANFIS) to predict of cadmium (cd) concentrations in the filyos river, turkey. Turkish Journal of Fisheries and Aquatic Sciences, 18(12), 1333-1343.

[72] Starrett, S. K., Starrett, S. K., Najjar, Y., Adams, G., \& Hill, J. (1998). Modeling pesticide leaching from golf courses using artificial neural networks. Communications in Soil Science and Plant Analysis, 29(19-20), 3093-3106.

[73] Suspended sediment estimation is very important to manage of the water resources, environments. As directly measuring sediment load of rivers is time consuming, expensive, studies have been made to develop sediment rating curve, (SRC), regression methods, artificial intelligence techniques for simulation processes with limited knowledge of the physics. In most rivers, et al. Suspended sediment estimation of skunk river in usa using fuzzy logic model

[74] Swain, P. C., \& Umamahesh, N. V. (2003). Stream flow forecasting using neuro-fuzzy inference system. Indian Journal of Power and River Valley Development, 53(5/6), 81-85.

[75] Tao, Y., Li, Y., Zhou, R., Chu, D., Su, L., Han, Y., \& Zhou, J. (2016). Neuro-fuzzy modeling to predict physicochemical and microbiological parameters of partially dried cherry tomato during storage: Effects on water activity, temperature and storage time. Journal of Food Science and Technology, 53(10), 36853694. 
[76] Umamaheswari, G. R., \& Kalamani, D. (2014). Fuzzy logic model for prediction of groundwater level in amaravathi river minor basin. International Journal of Mathematics Trends and Technology, 11, 46-50.

[77] won Seo, I., Yun, S. H., \& Choi, S. Y. (2016). Forecasting water quality parameters by ANN model using pre-processing technique at the downstream of cheongpyeong dam. Procedia Engineering, 154, 1110-1115.

[78] Yesilnacar, M. I., Sahinkaya, E., Naz, M., \& Ozkaya, B. (2008). Neural network prediction of nitrate in groundwater of harran plain, turkey. Environmental Geology, 56(1), 19-25.

[79] Zounemat-Kermani, M., \& Teshnehlab, M. (2008). Using adaptive neuro-fuzzy inference system for hydrological time series prediction. Applied Soft Computing, 8(2), 928-936. 